$$
\begin{aligned}
& \text { SAN1097.00706 } \\
& \text { CONF-97061/3-1 }
\end{aligned}
$$

\title{
PROPOSED INDUCTIVE VOLTAGE ADDER BASED ACCELERATOR CONCEPTS FOR THE SECOND AXIS OF DARHT
}

\author{
David L. Smith, David L. Johnson, John D. Boyes, \\ Michael D. Pelock, Finis W. Long, and John E. Maenchen \\ Sandia National Laboratories \\ P.O.Box 5800, Albuquerque, NM 87185-1184
}

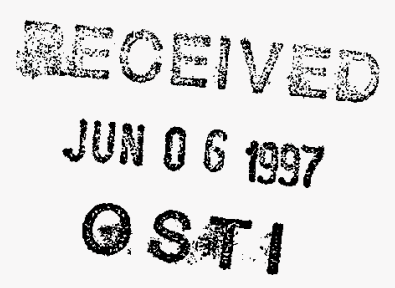

\section{ABSTRACT}

As participants in the Technology Options Study for the second axis of the Dual Axis Radiographic HydroTest (DARHT) facility located at Los Alamos National Laboratories, we have considered several accelerator concepts based on the Inductive Voltage Adder (IVA) technology that is being used successfully at Sandia on the SABRE and HERMES-III facilities. The challenging accelerator design requirements for the IVA approach include: $\geq 12-\mathrm{MeV}$ beam energy; 60-ns electrical pulse width; $\leq 40-\mathrm{kA}$ electron beam current; $\sim 1-\mathrm{mm}$ diameter e-beam; four pulses on the same axis or as close as possible to that axis; and an architecture that fits within the existing building envelope. To satisfy these requirements our IVA concepts take a modular approach. The basic idea is built upon a conservative design for eight ferromagnetically isolated 2-MV cavities that are driven by two 3 to $4-\Omega$ water dielectric pulse forming lines (PFLs) synchronized with laser triggered gas switches. The $100-\Omega$ vacuum magnetically insulated transmission line (MITL) would taper to a needle cathode that produces the electron beam(s). After considering many concepts we narrowed our study to the following options: A) Four independent single pulse drivers powering four single pulse diodes; B) Four series adders with interleaved cavities feeding a common MITL and diode; C) Four stages of series PFLs, isolated from each other by triggered spark gap switches, with single-point feeds to a common adder, MITL, and diode; and D) Isolated PFLs with multiplefeeds to a common adder using spark gap switches in combination with saturable magnetic cores to isolate the non-energized lines. We will discuss these options in greater detail identifying the challenges and risks associated with each.

\section{INTRODUCTION}

Inductive voltage adders are a relatively common technology at Sandia National Laboratories (SNL) for efficiently collecting the summed output of a pulsed-power driver and delivering it to a load via vacuum power flow. A typical adder configuration of eight inductively isolated cavities driving a coaxial vacuum MITL is shown in Fig. 1. The SNL machines have ranged from four to twenty cavities that drive

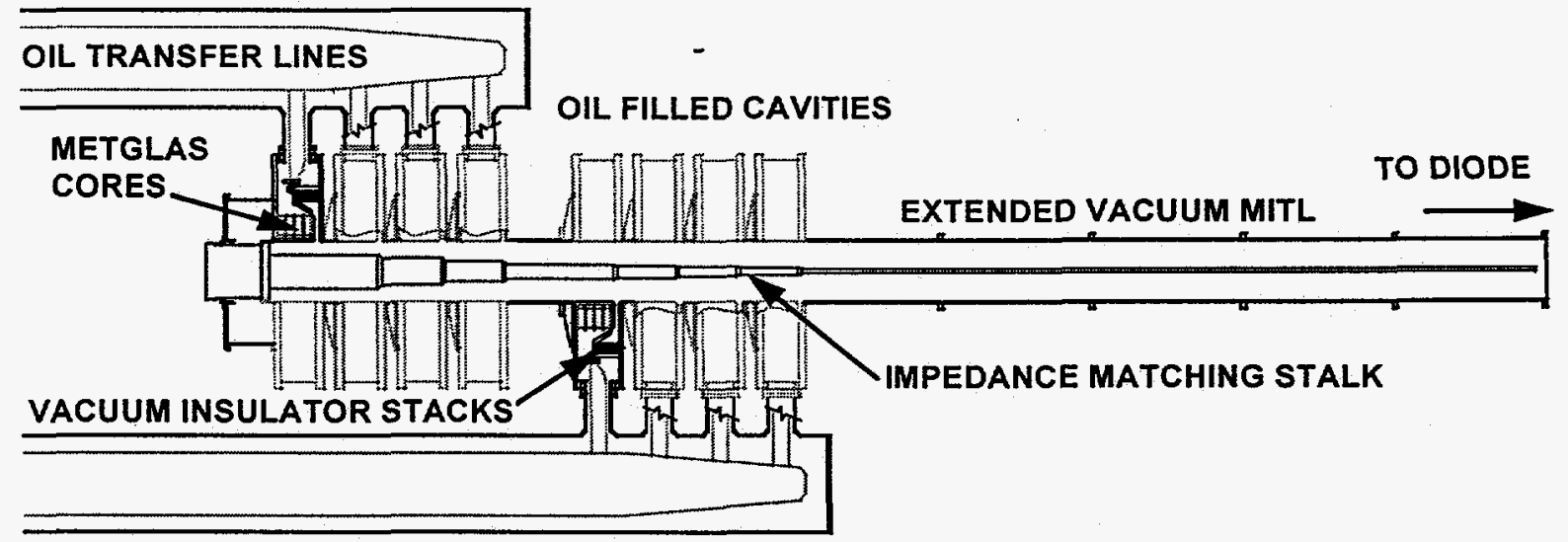

Fig. 1 A typical Sandia IVA design for DARHT applications shows the long extended MITL.

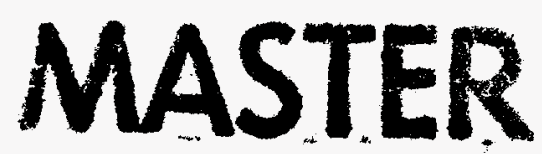




\section{DISCLAIMER}

This report was prepared as an account of work sponsored by an agency of the United States Government. Neither the United States Government nor any agency thereof, nor any of their employees, make any warranty, express or implied, or assumes any legal liability or responsibility for the accuracy, completeness, or usefulness of any information, apparatus, product, or process disclosed, or represents that its use would not infringe privately owned rights. Reference herein to any specific commercial product, process, or service by trade name, trademark, manufacturer, or otherwise does not necessarily constitute or imply its endorsement, recommendation, or favoring by the United States Government or any agency thereof. The views and opinions of authors expressed herein do not necessarily state or reflect those of the United States Government or any agency thereof. 


\section{DISCLAMMER}

Portions of this document may be illegible in electronic image products. Images are produced from the best available original document. 
MITLs at either polarity with output impedances from $20 \Omega$ to $150 \Omega$ and output voltages of $4 \mathrm{MV}$ to $20 \mathrm{MV}$. The ribbon-wound cores are composed of a ferromagnetic alloy with the commercial trade name Metglas. ${ }^{2}$ This configuration is commonly used for linear induction accelerators (LIA) where an electron beam is guided by magnetic fields through the acceleration acvities. To efficiently transport high currents, we replace the drifting electron beam with a cantilevered metal pipe (the inner cylinder of the MITL) which is tapered at each cavity output feed gap according to the impedance requirements to efficiently couple to the diode load. By replacing an electron beam with a conducting cylinder, IVAs avoid the beam transport, stability, and focusing issues associated with LIAs. The summed cavity voltages are delivered to the load without significant losses. Bent MITLs have been demonstrated and allow flexibility in the diode locations. For radiographic applications, the single-gap foilless diodes are immersed in a pulsed magnetic field of 20 to $50 \mathrm{~T}$, which serves to both maintain a small diameter, high brightness beam and to filter out the low quality electron sheath current from the upstream MITL. Experimental investigations of this type of diode have been documented. ${ }^{3,4,5}$

The typical SNL IVA pulsed-power source consists of an oil-insulated Marx generator, a waterdielectric intermediate store capacitor (ISC) or transfer capacitor, a laser-triggered multi-stage $\mathrm{SF}_{6}$ gas switch, and two or more water-dielectric coaxial PFLs with self-breaking water or gas switches. The tools we use to iteratively design and model the pulsed-power components include the SCREAMER circuit simulation $\operatorname{code}^{6}$ and electrostatic field solvers like ELECTRO 7 along with dielectric breakdown and flashover criteria similar to that originated by J.C. Martin. ${ }^{8}$ Since we have validated our modeling techniques by benchmarking against the SABRE and HERMES-III experimental measurements, we are confident in applying them to predict DARHT IVA performance.

When recent proof-of-principle tests on SABRE ${ }^{3,4}$ indicated that our IVA technology could be a viable candidate for the second arm of the DARHT facility, we prepared a number of IVA concepts for consideration in the Technical Option Study (TOS). The other approaches considered by the TOS review panel for the completed DARHT facility in 2001 are the short pulse and chopped long pulse applications of LIA technology. This paper summarizes the results of our narrowing the original nine Sandia concepts to four possibilities that would then be subject to more detailed analysis.

Some pulsed-power details which are common to all of the concepts are indicated in Table I. A simulated diode voltage waveform that satisfies the DARHT requirements is shown in Fig. 2 . This SCREAMER prediction has a slightly increasing ramp instead of a flat top.

Table I. Pulsed Power Description for the IVA Approaches.

$\begin{array}{lcccc}\text { Adder: } & 8 \text { Cavities } & \geq 12 \mathrm{MV} & 120 \mathrm{kA} & 100 \Omega \\ \text { PFLs: } & \text { 2/Adder } & 3.1 \mathrm{MV} & \leq 40 \mathrm{~ns} & 3.13 \Omega \\ \text { ISCs: } & \text { 1/Adder } & 2.6 \mathrm{MV} & 80 \mathrm{~ns} & 48.7 \mathrm{nF} \\ \text { Marx } & \text { 1/Adder } & 30 \mathrm{Caps} & 3 \mu \mathrm{F} / \mathrm{Cap} & \begin{array}{c}77 \mathrm{kV} \\ \text { Charge }\end{array}\end{array}$

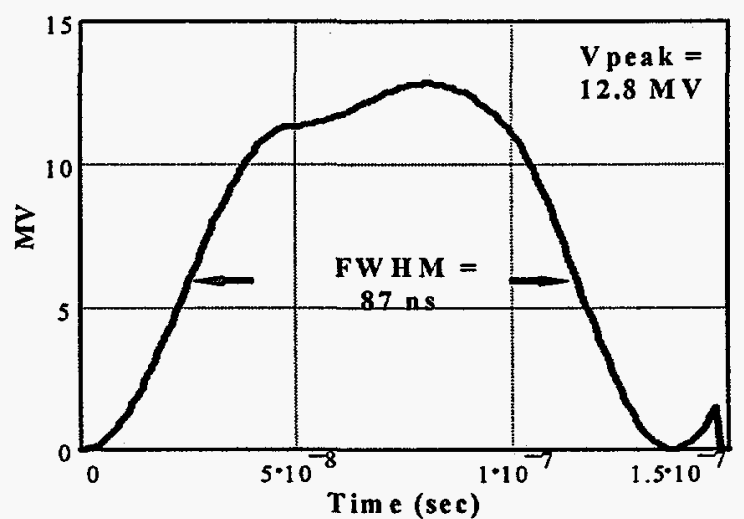

Fig. 2 Adder output voltage.

\section{CONCEPT A: FOUR INDEPENDENT SINGLE-PULSE ACCELERATORS}

Description Our baseline proposal to the DARHT project office is four identical, but independent, accelerators with separate single-pulse diodes. Figure 3 is a scale layout showing the four accelerators packaged within the building as close as possible to the firing point target area. The adder section occupies approximately $15 \mathrm{~m}$ (less than one-fourth of the accelerator hall length). This lowest risk concept, with the diodes offset from each other by $8^{\circ}$, approaches the DARHT criteria of multiple pulses along a common axis.

Advantages and Disadvantages This baseline accelerator design remains within known technology parameter space, since it includes only single-pulse drivers and diodes. Hence, no issues regarding the 


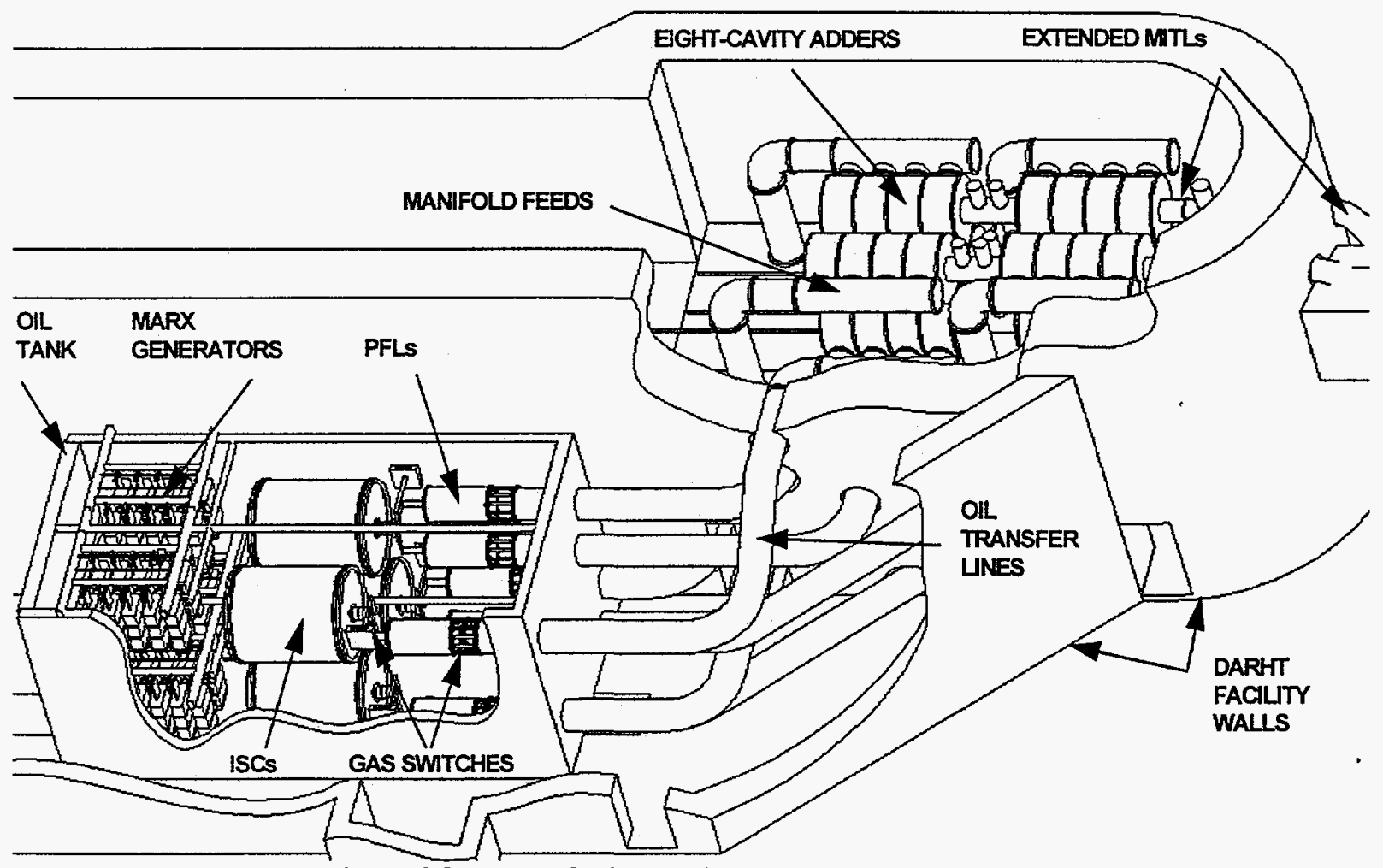

Fig. 3 The top view of Concept A shows the compact $2 \times 2$ packing configuration.

multi-pulsing of a diode assembly need to be addressed. No active inter-pulse cavity core reset network is required since each adder provides only one pulse. The multi-axis approach also offers four target viewing angles $\geq 8^{\circ}$ with arbitrary timing. This $3-D$ configuration requires $3-D$ radiographic analysis technique development by the customer. Concept $A$ requires the maximum amount of hardware, since none of the components are reused for more than one pulse per test.

\section{CONCEPT B: SERIES ADDERS}

Description A concept of four independent pulsed-power drivers with series adders that have a single MITL and diode is shown in the Fig. 4. The Marx, ISC, and PFL assemblies feed interleaved cavities that form a common long adder. The pulsed-power components are arranged to minimize the lengths of the oil transfer lines, which do have some effect on the pulse shapes. The cavities are interleaved so that the respective cavities for successive pulses will see a similar adder load impedance. In each grouping of four cavities, the first cavity is driven by the first pulse, the second cavity is driven by the second pulse, and so on.

Advantages and Disadvantages The single-shot driver technology is based on the same wellunderstood pulsed power as the previous concept. The single diode and magnet system simplifies the load hardware but requires developing a multi-pulse e-beam target capability, which is considered the most difficult physics issue. This concept requires an extra long cantilevered MITL stalk generating concern for large stresses and deflections; however, the design was not pursued far enough to quantify the concern. Further investigation of the MITL power flow losses into the neighboring unenergized cavities is definitely required. Minimizing the loss with partial core reset biasing plus compensating with additional pulse energy would address this issue.

\section{CONCEPT C: SERIES PFLS, MULTI-PULSE ADDER}

Description Figure 5 demonstrates how the water dielectric coaxial PFLs may be connected in series, with each output switch isolating its PFL from the previous line. In this figure four separate oil tanks are 


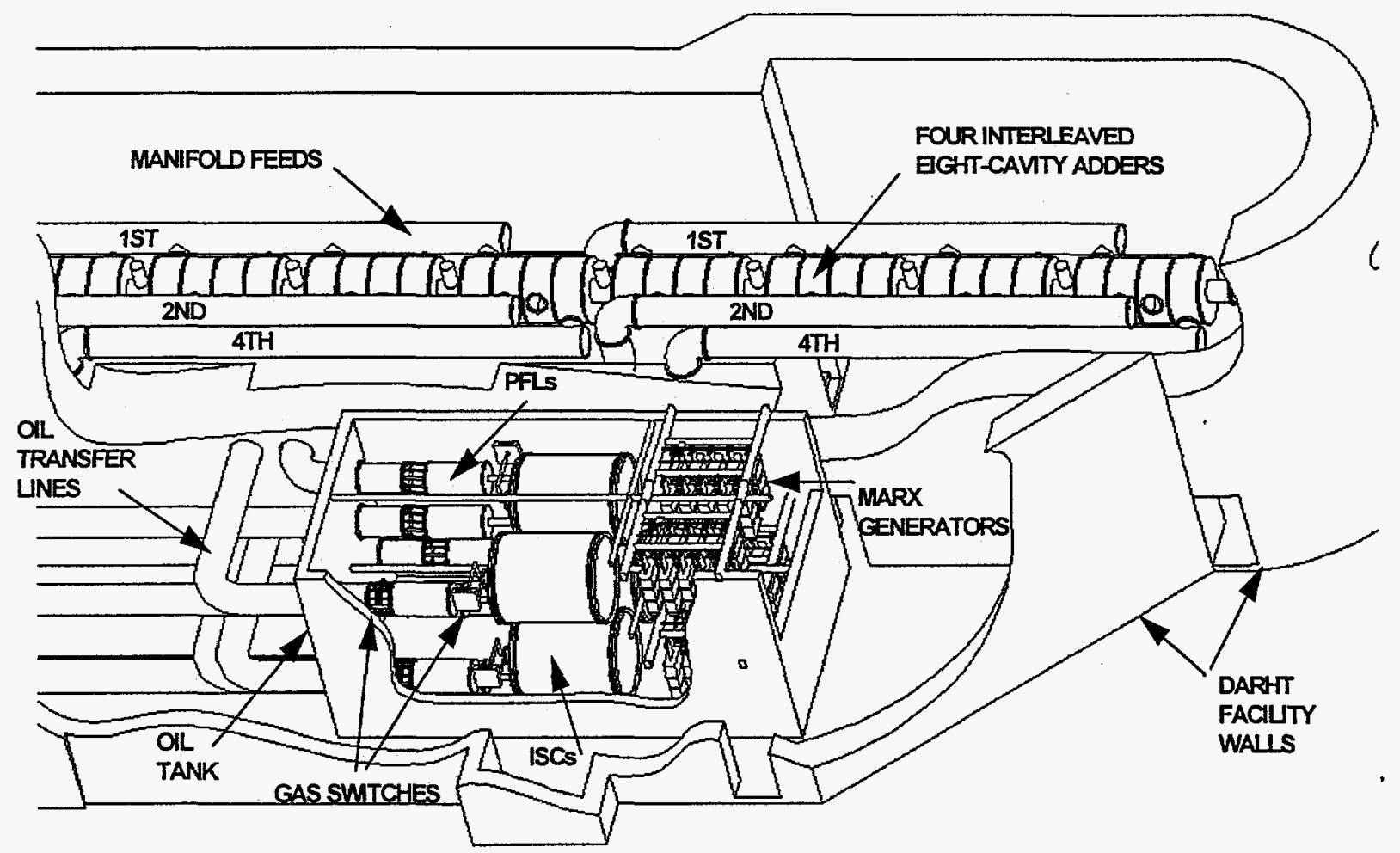

Fig. 4 The long 32-cavity adder of Concept B would be about $50 \%$ longer than HERMES-III.

shown configured to minimize the oil volume, minimize the oil transfer line lengths, and improve isolation between the prime power sources. The independent Marx generators can successively charge the water lines beginning with the ones closest to the cavities. The group of eight cavities forming the adder grow in length and diameter, with respect to the previous concepts, to account for the additional Metglas (from

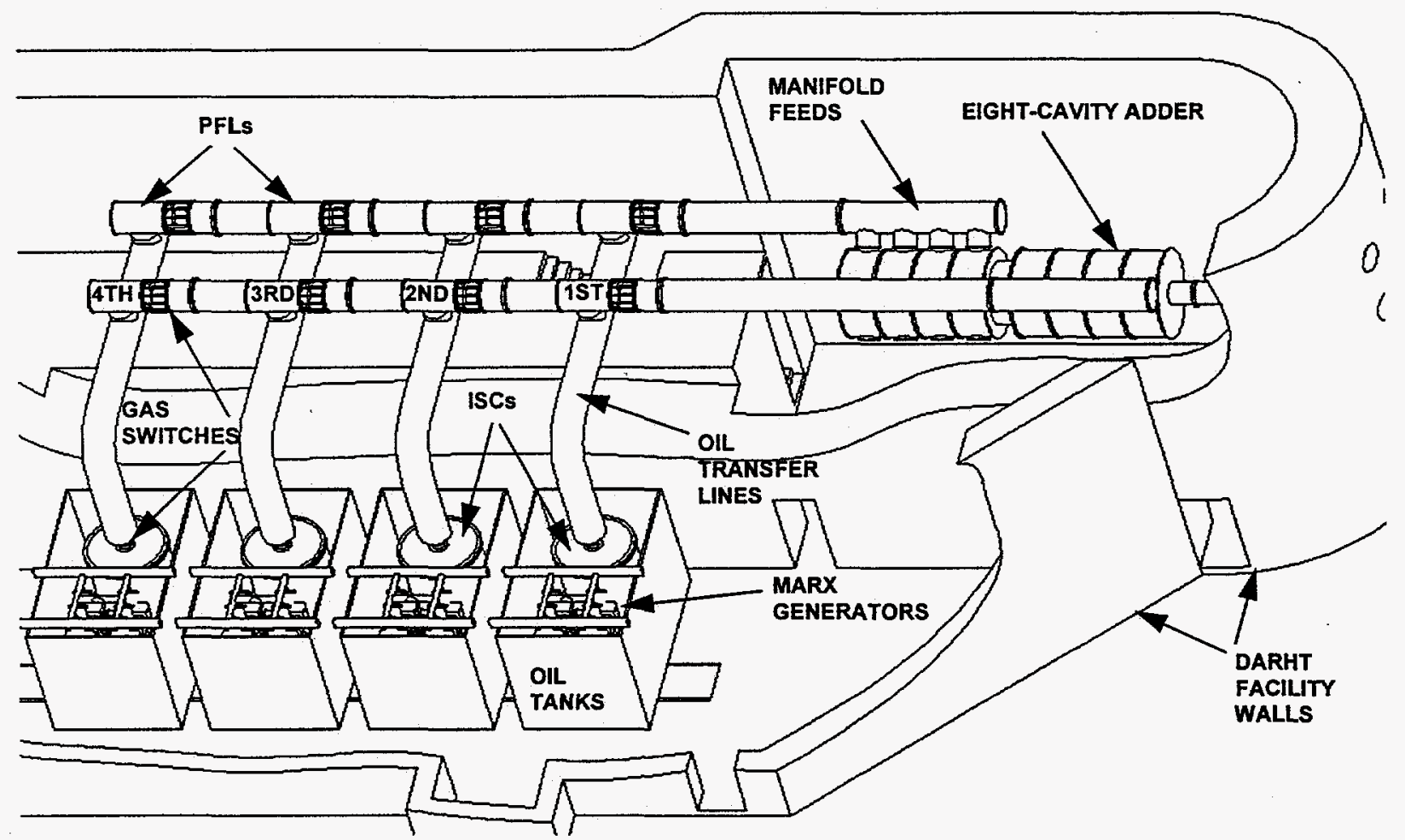

Fig. 5 This layout of Concept $C$ shows an efficient use of the available facility space. 
0.11 to $0.44 \mathrm{~V}$-s) needed to provide isolation from ground for all four pulses, assuming an active core reset system is not used.

Advantages and Disadvantages Concept $\mathrm{C}$ also represents a low-risk approach with known pulsepower technology for most of the components. Two series PFLs have been successfully operated at Los Alamos National Laboratories in the PHERMEX facility to one-quarter of these proposed voltages. Only a single eight-cavity adder, MITL, diode and support system are required. Careful packaging of the components is required to fit the facility in a compact, accessible, and maintainable arrangement. The diode, MITL, and cavities all require developing a multi-pulse capability. The PFL output switches have to hold off the downstream line charging pulse, which is an engineering development issue. Subsequent pulses must be shaped and have sufficient amplitude to compensate for losses to the PFL charging feeds from the ISCs. The MITL lengthens over that of the baseline concept by the summed cavity lengths.

\section{CONCEPT D: ISOLATED PFLS, MULTI-PULSE ADDER}

Description The final configuration considered is a higher-risk, high-value technical option, shown in Fig. 6 , which could be developed in parallel with the four independent accelerators baseline and phase implemented as R\&D mitigates the risk. The Marx, ISC, and PFL systems are similar to those of the baseline design, but modified to minimize late time energy management issues. They feed common oil transfer lines driving one adder assembly. The four pulses are isolated from each other by blocking networks consisting of different combinations of Metglas cores and laser triggered isolation switches. Again, these cavities are larger than those for the first two design concepts in terms of additional housing for the Metglas material and vacuum insulator stacks because the volt-seconds and design breakdown stresses scale as four times the effective pulse length, as opposed to the case for a single pulse.

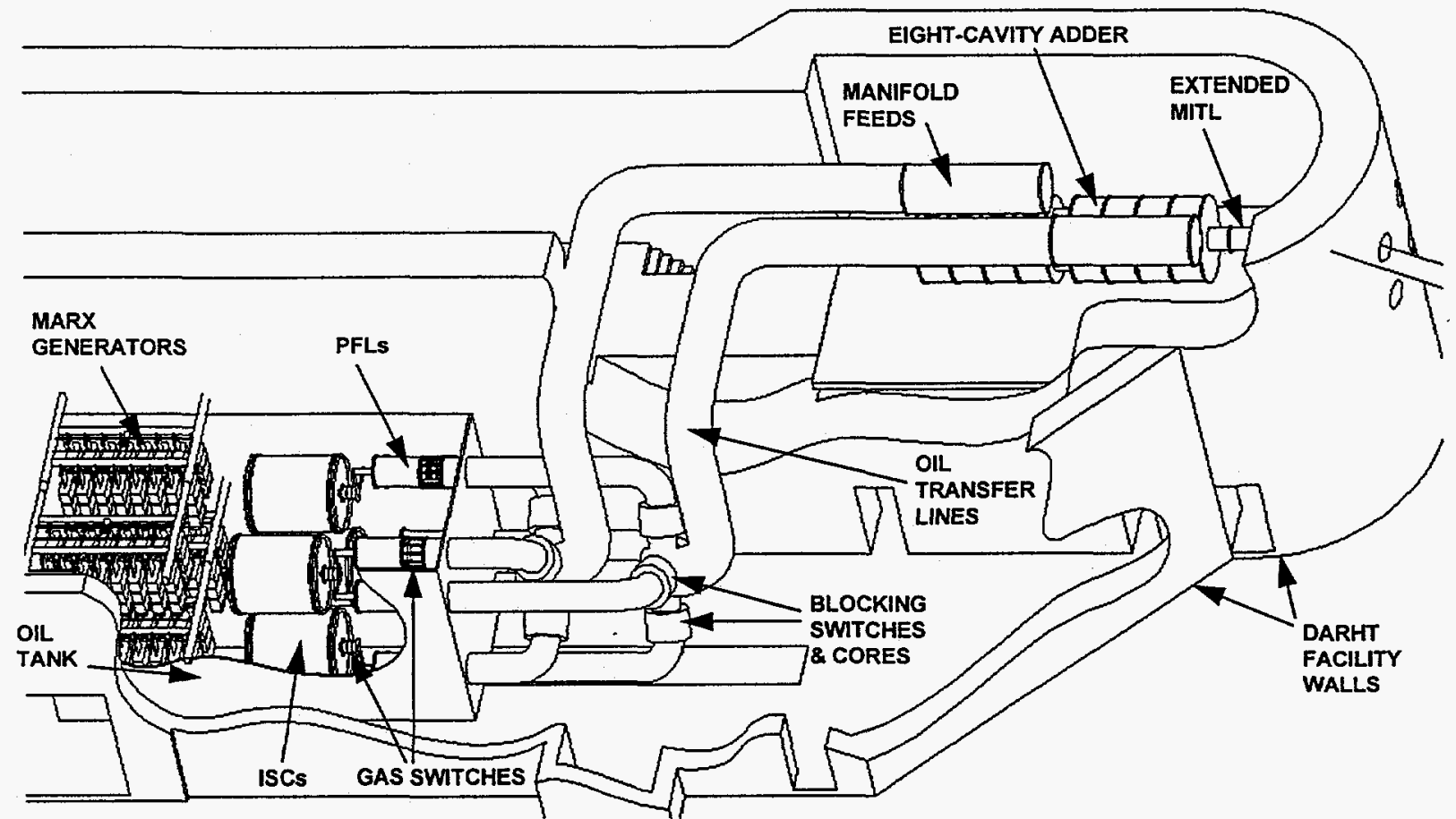

Fig. 6 The isolated PFLs of Concept D drive only two oil transfer lines.

A combination of laser triggered gas switches and Metglas blocking networks are necessary to achieve four well-defined pulses. As seen in Fig. 7, the PFL pulses are delivered by short oil lines to the blocking system which feeds the common oil transfer lines. The cores are forward biased for the main forward going pulse, but they are effectively reversed biased for the secondary pulses on their output sides. The laser triggered switches initially block all secondary pulses until they have to be closed. Advantages and Disadvantages The pulsed-power technology is understood and accepted as low risk for most of the components. The blocking switches and cores also serve the dual functions of sharpening 
the rise on the forward-going pulse and eliminating any prepulse. Only two oil transfer lines are required along with a single adder, MITL, diode and support system. The coaxial oil transfer lines and the cavity vacuum insulator barriers grow to accommodate the four-pulse field stress increases of $59 \%$ and $26 \%$, respectively. Some development of the blocking network would be required; the blocking switch standoff and triggering operations are in a shorter pulse length and lower voltage regime than on other SNL systems. The MITL lengthens over that of the baseline concept by the summed cavity lengths. The diode, MITL, cavities, and oil transfer lines all require developing a multi-pulse capability.

\section{SUMMARY AND CONCLUSIONS}

The Concepts $B, C$, and $D$ all require a higherrisk, multi-pulse, single-axis diode, which has yet to be demonstrated. Otherwise, all concepts appear to be

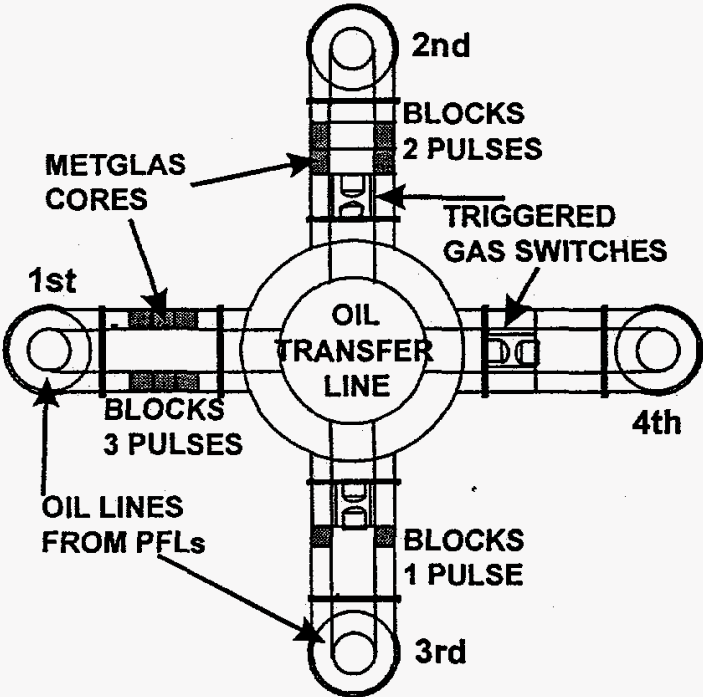

Fig. 7 End view of blocking network. within a similar reasonable risk regime and differ only by some advantage/disadvantage tradeoffs. Concepts $C$ and $D$ would need seven laser switch trigger systems to support four pulses, while $A$ and $B$ would need four, assuming that the PFL output gas switches operate suitably in a self-break mode. The baseline (Concept A) was chosen because of the minimal risk of four independent diodes with viewing flexibility. Being the most hardware intensive case, the baseline has four MITLs that require alignment verification plus four diode/magnet assemblies and their respective support systems. Even so, the estimated facility price remains far less than other technologies. With the versatility indicated in our different concepts and our history with existing similar technology facilities, the IVA approach appears to be well suited for adding radiography to its growing list of applications.

\section{ACKNOWLEDGMENTS}

The authors wish to thank Chuck Harjes from whose initial study our Concept $D$ evolved. Mike Burns should be commended for organizing and facilitating the TOS and the final assessment review panel as a multi-National Laboratory collaboration to jointly search for the best solution. Sandia is a multiprogram laboratory operated by Sandia Corporation, a Lockheed Martin Company, for the United States Department of Energy under Contract No. DE-AC04-94AL85000.

\section{REFERENCES}

1. J.J. Ramirez, et al., "The HERMES-III Program," Proc. 6th IEEE Pulsed Power Conf., Arlington, VA, p. 294, Jun 1987.

2. METGLAS is Allied Corporation's registered trademark for an amorphous alloy of metals.

3. M.G. Mazarakis, et al., "Pencil-like $\mathrm{mm}$-size Electron Beams Produced with Linear Inductive Voltage Adders," Applied Physics Letters, Vol. 70, No. 7, pp. 832-834, 17 Feb 1997.

4. M.G. Mazarakis, et al., "Experiments Investigating the Generation and Transport of $10-12 \mathrm{MeV}, 30-\mathrm{kA}$, mm-size Electron Beams with Linear Inductive Voltage Adders," Proc. 1997 Particle Accelerator Conf., Vancouver, BC, Canada, 12-16 May 1997.

5. M.G. Mazarakis, et al., "Inductive Voltage Adder (IVA) for Submillimeter Radius Electron Beam," Paper O16-1,2 Proc. 11th IEEE International Pulsed Power Conf., Baltimore, MD, 29 Jun-2 Jul 1997.

6. M.L. Kiefer, et al., "SCREAMER - A Pulsed Power Design Tool, User's Guide for Version 2.0," Sandia National Labs, Albuquerque, NM, 25 Aug 1995.

7. "ELECTRO Users and Technical Manual," Version 4.0, Integrated Engineering Software inc., 46-1313 Border PI., Winnipeg, Manitoba, Canada, R3G $2 X 7$.

8. J.C. Martin, "Nanosecond Pulse Techniques," Internal Report SSWAJJCM/704/49, AWRE, Aldermaston, Berkshire, England, Apr 1970. 